\title{
Super Behaviour: A Note on
} Young Australian Adults' Engagement With Their Superannuation Accounts

\author{
Malcolm Anderson', Martin Clark², Ian Ramsay ${ }^{3}$ and Chander Shekhar ${ }^{4}$
}

\begin{abstract}
We examine the behaviour and attitudes towards superannuation of 25-34 year old Australians. Our results suggest that they are generally uninterested in their superannuation accounts. They seldom read the information provided by their funds, rarely change their fund, and a majority of them do not make voluntary contributions. Overall the results suggest significant lack of interest in, and engagement and concern with issues related to their retirement planning.
\end{abstract}

JEL Classification: D14

Keywords: Superannuation, young people, fund change, voluntary contribution, Australia.

\footnotetext{
${ }^{1}$ University of Melbourne - Faculty of Education

${ }^{2}$ Melbourne Law School and Law Department, London School of Economics and Political Science

${ }^{3}$ Melbourne Law School

${ }^{4}$ University of Melbourne; Financial Research Network (FIRN)
} 


\section{Introduction}

In Australia superannuation forms two of the three pillars of the retirement income system. The two pillars related to superannuation are the superannuation guarantee (compulsory employer contributions) and voluntary superannuation contributions (made by individual fund members). These operate in conjunction with the third pillar of the age pension which is funded by current taxpayers. In 1992, as a result of the establishment of the Superannuation Guarantee Charge, superannuation coverage was extended to more than $90 \%$ of the Australian workforce. The Australia superannuation scheme is now the fourth largest in the world (Deloitte, 2013). There are currently 30.7 million superannuation accounts in Australia (APRA, 2014) and the total superannuation assets were valued at $\$ 1.8$ trillion dollars in 2014 , and those assets grew by 15.7\% over the 2012/13 financial year (APRA, 2014; Deloitte, 2013).

Given the size and scope of Australia's superannuation scheme, it is both a massive industry and an important instrument of modern social planning aimed at supporting and sustaining Australia's increasingly ageing and retiring population. However, previous studies have shown that knowledge, behaviour, and attitudes of Australians towards superannuation are less than desirable. Young adults generally fare worse than the general population on all aspects of superannuation knowledge and behaviour - they are far from retirement, have had little exposure to financial decision making related to retirement, and are more concerned with issues such as establishing a career, starting a family, and paying for rent and education, among others. However this lack of engagement with superannuation also prevents them from making important and effective planning decisions which may have significant consequences later in life. These inferences about young adults' behaviour, however, have been based on studies that do not necessarily examine representative populations (e.g. use university students) or are extracted from studies that use large sample from general population, of which young Australians only make up a small proportion of participants.

Our study specifically examines the superannuation behaviour of young Australians (25-34 years old) and examines their knowledge, behaviour, and attitudes. The results are, on average, even less encouraging than those reported by earlier studies. This note presents results related to the behaviour of young Australians towards their superannuation - we examine how much attention they pay to the information provide by their superannuation funds, whether they actively manage their superannuation account by changing investment options, switching funds, and by making voluntary contributions. The next section provides a brief summary of current literature on superannuation behaviour. Section 3 describes the data used in the study, followed by Section 4 that describes and analyses the results of our study. Section 5 concludes and briefly discusses some policy implications of the study.

\section{Empirical literature on behaviour}

The empirical literature on behaviour of Australian adults with regards to superannuation has analysed various aspects such as skills, interaction with superannuation funds and the like. Parrish and Delpachitra (2012) analysed the behaviour associated with fund selection by surveying undergraduate students at Flinders University. After being presented with varying layouts and information, the participants were asked to choose a superannuation fund and an associated investment option. Parrish and Delpachitra (2012) found that fund selection was found to be influenced by the location of fee information, by risk labels, and by the employer. 
Another study, which was not restricted to young adults, found that financial literacy was strongly correlated with higher wealth accumulation and personal net worth (Bateman et al., 2012).

Information provided by superannuation funds has also been shown to influence the behaviour of account holders. Such information can be presented in various forms including both mandated and voluntary disclosures, educational material such as handbooks and seminars, and via websites and direct written communication with account holders, and may be provided by the fund as well by the employer. Ntalianis (2011) found that Australian university employees largely relied on written communication, followed by fund websites, educational seminars and counselling to make their decisions. University employees who attended financial seminars also subsequently exhibited greater understanding of retirement issues (Ntalianis and Wise, 2011). In an earlier study, young survey respondents (aged under 30) performed poorly by exhibiting a lack of understanding of basic ideas associated with superannuation in that they were generally unable to read the statements and understand issues related to retirement planning and employer contributions (Worthington, 2008).

In addition to the lack of financial literacy, disinterested behaviour by young Australians can be linked to the notion that as retirement is "too far away", young people consider it to be unimportant, and generally believe that thing will work out (Ntalianis and Wise, 2011). Examining behaviour without first establishing knowledge (or lack thereof) provides slightly different results. A recent study by AIST asked questions about engagement with superannuation funds, required superannuation retirement savings, and uses of superannuation. The results suggest that about $26 \%$ of young Australians (Gen Y group defined here as 14-34 years old) were interested in superannuation and believed that on average their superannuation would fund about $40 \%$ of their retirement. As this survey specifically focussed on engagement with the funds (without examining the respondents' knowledge about superannuation), it is difficult to draw any significant conclusions about the actual behaviour.

The current literature suffers from some limitations as it typically does not directly sample young adults in Australia. Studies that employ large samples drawn from the general population are only able to comment on a small number of young participants' attitudes towards superannuation. Although studies that exclusively utilize younger participants mitigate this concern, their samples may not be representative of the general young population. For instance, such studies typically involve currently enrolled university students; they do not use significant demographic information about the sample, do not control for any self-selection biases, and may not be representative of the general population. Studies such as that conducted by AIST do collect some demographic information but not delve closely into analysis of trends linked to this information (Tustin et al., 2014). Studies that exclusively use university students may be subject to other selection biases as university students are likely to be better educated, are more likely to have come from privileged backgrounds, and therefore are perhaps likely to show "better" results than the average population on financial and retirement knowledge. Additionally university students are probably less likely to have been exposed to factors that may be important in affecting superannuation knowledge, behaviour and attitudes, such as workforce involvement, experience with making long-term financial decisions (such as taking out a mortgage), or supporting a family. Finally, within the sample such biases may be further exacerbated by students' fields of study - education in fields such as business studies, economics, finance, and 
accounting may be more important than the general level of education completed in assessing superannuation knowledge, behaviour and attitudes.

\section{Data}

Our empirical study employed a 75-question online survey instrument distributed and managed by Pureprofile. The instrument was first distributed on 12 December 2013 and ran until 3 March 2014. We obtained 994 useable surveys with detailed personal and financial demographics. Reponses also include information about objective knowledge, behaviour (skills, conduct and self-assessment of knowledge), and attitudes. Factors favouring an online survey over a traditional phone survey included the ability to ask more detailed questions, allowing respondents more time and flexibility to answer questions, and the lower cost associated with the former. Additionally several similar studies on superannuation had used online surveys and there is support for the value of this approach. Ntalianis, who also employed an electronic questionnaire, suggests that the online survey approach is "regarded as the best method for gathering data from large unobservable populations". The online survey also allowed the inclusion of open-ended questions or listing exercises that are perhaps more easily conducted online rather than on phone. Although many respondents only left short responses to open-ended questions, some elaborated on their views and attitudes at length, as might be expected from a focus group roundtable.

We sampled young adults in Australia aged 25-34 who were members of at least one superannuation fund. We also collected demographic data on gender, age, location, whether or not a language other than English (LOTE) was spoken at home; details of current relationship status and number of children/dependants; current living arrangements and postcode; use of financial and communication products; details of completed education, including specific areas of study related to finance; income, current and past employment details; and similar information on partners and parents (if applicable). Table 1 provides a snapshot of our sample characteristics, where "urban" indicates a central or suburban location, while "region" includes any regional or rural locations. "Degree" indicates that the respondent holds a post-secondary qualification while "low education" indicates year 12 completion or less. "High income" and "low income" collects respondents from the top and bottom third of average income (i.e. top and bottom tercile) of the respondents, respectively.

Table 1: General demographical distribution of survey respondents

\begin{tabular}{lrrrrrrr}
\hline Characteristic & All & Male & Female & Urban & Region & Degree & Low Ed \\
& & & & & & & \\
Aged 25 to 29 & $\mathbf{5 1 . 7}$ & 51.9 & 51.6 & 51.8 & 51.7 & 51.5 & 53.6 \\
Aged 30 to 34 & $\mathbf{4 8 . 3}$ & 48.1 & 48.4 & 48.2 & 48.3 & 48.5 & 46.4 \\
Male & $\mathbf{5 0 . 3}$ & 100.0 & 0.0 & 50.3 & 50.3 & 51.0 & 51.9 \\
Female & $\mathbf{4 9 . 7}$ & 0.0 & 100.0 & 49.7 & 49.7 & 49.0 & 48.1 \\
Urban & $\mathbf{6 6 . 4}$ & 66.3 & 66.4 & 100.0 & 0.0 & 76.5 & 52.5 \\
Regional/Rural & $\mathbf{3 3 . 6}$ & 33.7 & 33.6 & 0.0 & 100.0 & 23.5 & 47.5 \\
& & & & & & & \\
\hline Characteristic & All & $25-29 y r s$ & $30-34 y r s$ & Hi_Inc & Low_Inc & English & LOTE \\
& & & & & & & \\
Aged 25 to 29 & $\mathbf{5 1 . 7}$ & 100.0 & 0.0 & 47.7 & 51.7 & 52.8 & 46.9 \\
\hline
\end{tabular}




\begin{tabular}{lrrrrrrr}
\hline Aged 30 to 34 & $\mathbf{4 8 . 3}$ & 0.0 & 100.0 & 52.3 & 48.3 & 47.2 & 53.1 \\
Male & $\mathbf{5 0 . 3}$ & 50.4 & 50.2 & 61.3 & 35.7 & 49.4 & 54.6 \\
Female & $\mathbf{4 9 . 7}$ & 49.6 & 49.8 & 38.7 & 64.3 & 50.6 & 45.4 \\
Urban & $\mathbf{6 6 . 4}$ & 66.4 & 66.3 & 78.9 & 54.7 & 62.4 & 84.9 \\
Regional/Rural & $\mathbf{3 3 . 6}$ & 33.6 & 33.7 & 21.1 & 45.3 & 37.6 & 15.1 \\
\hline
\end{tabular}

To obtain basic superannuation account details, the survey instrument required respondents to first indicate the age at which they first joined a superannuation fund and second to complete a detailed table on their superannuation accounts. That table required that they indicate various funds of which they are members of, and the estimated balance and the certainty of that estimate ("quite certain"; "estimate"; "guess"), their estimation of their partners' superannuation balance (if applicable), the number of times they have switched funds, which investment options they use, and details of voluntary contributions (how much money is contributed voluntarily and how often).

The superannuation balance data is reported in Table 2. The reported balances exhibit extreme values at the higher end of superannuation fund holdings, making it difficult to interpret the data. The mean amount of $\$ 40,271$ is highly affected by these extreme amounts and therefore we focus on medians and trimmed means (a mean with $10 \%$ of amounts on both ends of the spectrum excluded). The trimmed mean is $\$ 22,509$, the average of the "middle $80 \%$ " of the sample, and more realistically attuned to the median. The data in Table 2 indicates that the mean superannuation balance was significantly higher for males. It also suggests that there was no significant difference in mean balances for respondents from urban and regional locations, and between respondents with English and LOTE. However, as expected, higher degree holders, older respondents (30-34 years), and high income respondents all had significantly higher balances compared with those without degrees, younger respondents, and low income respondents respectively.

Table 2: Superannuation balances

\begin{tabular}{lr|rr|rr|rr}
\hline & All & Male & Female & Urban & Region & Degree & LowEd \\
Mean(\$) & $\mathbf{4 0 , 2 7 1}$ & 55,611 & $24,594^{*}$ & 37,504 & 45,946 & 53,407 & $23,142^{*}$ \\
Median(\$) & $\mathbf{2 0 , 0 0 0}$ & 22,000 & 18,000 & 20,000 & 17,000 & 23,000 & 14,000 \\
Trimmed Mean(\$) & $\mathbf{2 2 , 5 0 9}$ & 23,949 & $21,153^{*}$ & 22,700 & 22,119 & 23,585 & $20,407^{*}$ \\
\hline & All & $25-29 y r s$ & $30-34 y r s$ & Hi_Inc & Low_Inc & English & LOTE \\
Mean(\$) & $\mathbf{4 0 , 2 7 1}$ & 31,160 & 49,903 & 56,059 & $17,191^{* *}$ & 42,131 & 31,507 \\
Median(\$) & $\mathbf{2 0 , 0 0 0}$ & 15,132 & 25,000 & 30,000 & 10,000 & 20,000 & 20,000 \\
Trimmed Mean(\$) & $\mathbf{2 2 , 5 0 9}$ & 19,585 & $25,811^{* *}$ & 27,845 & $15,257^{* *}$ & 22,570 & 22,252 \\
\hline
\end{tabular}

Hi_Inc and Low_Inc indicate respondents in the top and bottom tercile of average incomes respectively.

Statistical significance of differences between observations for adjacent sub-groups (e.g. between Male and Female sub-groups) is estimated using t-test and $*$ and $* *$ indicate significance at 0.05 and 0.01 percent respectively. 


\section{Main Results}

We now present our main results as they pertain to the behaviour of young Australians with superannuation accounts. Given that respondents have superannuation accounts, we assess their behaviour by asking questions that determine how often they check the accounts. This is followed by ascertaining which aspects of information communicated by the superannuation fund they pay attention to. Subsequently we determine how the respondents actively engage with their superannuation accounts - whether they change investment choices (and funds) and whether they make voluntary contributions.

Table 3 presents the results related to how often respondents check their accounts. About one quarter $(24.3 \%)$ "Hardly ever or never" check their accounts. Notably within this group women and respondents without degrees engage in this behaviour more often than men and respondents with degrees respectively. Interestingly, at the other end of the spectrum both of these groups are only more likely to check their accounts when they receive the statements. There is no significant difference in checking behaviour between the younger (25-29 years) and the slightly older (3034 years) cohorts of the sample.

Table 3: How often do respondents check their superannuation account?

\begin{tabular}{|c|c|c|c|c|c|c|c|}
\hline & All & Male & Female & Urban & Region & Degree & LowEd \\
\hline When receive statement & 21.4 & 18.2 & $24.7^{*}$ & 20.1 & 24.0 & 18.4 & $28.3^{* *}$ \\
\hline Daily or Weekly & 4.9 & 6.0 & 3.8 & 5.5 & 3.8 & 6.8 & 3.0 \\
\hline Monthly to six monthly & 39.6 & 45.6 & $33.5 * *$ & 40.0 & 38.7 & 43.9 & $29.4^{* *}$ \\
\hline Yearly & 9.8 & 8.9 & 10.7 & 10.4 & 8.5 & 11.5 & 6.6 \\
\hline \multirow[t]{2}{*}{ Hardly ever or never } & 24.3 & 21.4 & $27.3^{*}$ & 24.0 & 25.0 & 19.3 & $32.7^{* *}$ \\
\hline & All & $25-29 y r s$ & $30-34 y r s$ & Hi_Inc & Low_Inc & English & LOTE \\
\hline When receive statement & 21.4 & 21.3 & 21.5 & 18.4 & $25.8^{*}$ & 23.1 & $13.3 * *$ \\
\hline Daily or Weekly & 4.9 & 4.8 & 5.1 & 6.9 & $3.3^{*}$ & 3.9 & $9.7 * *$ \\
\hline Monthly to six monthly & 39.6 & 38.4 & 40.8 & 47.4 & $29.3^{* *}$ & 39.0 & 42.2 \\
\hline Yearly & 9.8 & 8.7 & 10.9 & 10.8 & 8.9 & 10.0 & 8.7 \\
\hline Hardly ever or never & 24.3 & 26.8 & 21.7 & 16.5 & $32.8^{* *}$ & 23.9 & 26.2 \\
\hline
\end{tabular}

Each observation indicates the proportion of subjects who chose that particular response. Hi_Inc and Low_Inc indicate respondents in the top and bottom tercile of average incomes respectively. Statistical significance of differences between observations for adjacent sub-groups (e.g. between Male and Female sub-groups) is estimated using t-test and $*$ and $* *$ indicate significance at 0.05 and 0.01 percent respectively.

Now we examine how much of (and what specifically) of the information provided by the superannuation funds is read by the respondents. We note that these responses assume that the respondents actively look at their statements and at the other communications. Table 4 indicates that overall about $10 \%(5.7 \%+3.5 \%$ "who don't recall receiving fund statements") of the people surveyed do not pay any attention to the statement. Just looking at the balance - as $13.5 \%$ respondents do - comes close to not reading anything as it is difficult to imagine a person obtaining any substantive insight by looking at a number. Respondents without a degree are more likely to only look at the balance, as are low income participants. Although females (when compared with males) are less likely to read everything, they pay more attention to the key figures provided when they do. 
Table 4: How much do the respondents read?

\begin{tabular}{lr|rr|rr|rr}
\hline & All & Male & Female & Urban & Region & Degree & LowEd \\
All or most & $\mathbf{3 0 . 6}$ & 36.9 & $24.3^{* *}$ & 29.6 & 32.8 & 33.9 & $25.6^{*}$ \\
Key figures & $\mathbf{4 6 . 7}$ & 41.9 & $51.6^{* *}$ & 48.2 & 43.6 & 47.4 & 43.7 \\
Balance only & $\mathbf{1 3 . 5}$ & 13.8 & 13.2 & 13.0 & 14.5 & 11.3 & $20.4^{* *}$ \\
None of it & $\mathbf{5 . 7}$ & 4.0 & $7.4^{*}$ & 5.7 & 5.6 & 4.8 & 5.3 \\
& & & & & & & \\
\hline & All & $25-29 y r s$ & $30-34 y r s$ & Hi_Inc & Low_Inc & English & LOTE \\
All or most & $\mathbf{3 0 . 6}$ & 27.1 & $34.5^{*}$ & 37.5 & $25.0^{* *}$ & 29.8 & 34.5 \\
Key figures & $\mathbf{4 6 . 7}$ & 48.9 & 44.4 & 45.9 & 44.9 & 48.1 & 40.2 \\
Balance only & $\mathbf{1 3 . 5}$ & 14.3 & 12.7 & 10.8 & $17.1^{*}$ & 13.1 & 15.5 \\
None of it & $\mathbf{5 . 7}$ & 6.7 & 4.7 & 4.2 & $8.1^{*}$ & 6.1 & 3.9 \\
\hline
\end{tabular}

Each observation indicates the proportion of subjects who chose that particular response. Hi_Inc and Low_Inc indicate respondents in the top and bottom tercile of average incomes respectively. Statistical significance of differences between observations for adjacent sub-groups (e.g. between Male and Female sub-groups) is estimated using t-test and $*$ and $* *$ indicate significance at 0.05 and 0.01 percent respectively.

The differences between men and women and between degree and non-degree holders are also apparent when we consider what section(s) of the statement they pay attention to. As indicated in Table 5, although fewer women (when compared with men) pay attention to the letters, handbooks, and investment options, this is reversed when information about fees and charges is involved. Non-degree holders are seemingly less concerned with fees and charges and past performance than degree holders. Consistent with prior results, we find no significant differences between behaviour of the two age based cohorts with one exception. The older respondents pay more attention to past performance, which is consistent with the notion that as employees get older, and as retirement looms a little closer, they become both more aware of and more concerned about, the performance of their investments. The data also indicate that the vast majority of respondents do check their balance as this proportion varies little across the twelve categories in Table 5. However, as noted earlier, this is hardly indicative of taking an active interest in the information provided by the superannuation fund. Taken together, the results reported in Tables 3-5 paint a slightly more favourable picture than presented by the ANZ 2011 Financial Literacy Survey in which $69 \%$ of respondents read their statements, whereas about $77 \%$ of respondents in our survey read (at least) some part of the statement. Additionally, when asked what they looked for when reading their statement, $14 \%$ of the respondents in the ANZ survey read their balance, whereas more than $90 \%$ of our respondents did.

Table 5: What do the respondents pay attention to?

\begin{tabular}{ll|ll|ll|ll}
\hline & All & Male & Female & Urban & Region & Degree & LowEd \\
Letter from fund & $\mathbf{2 0 . 3}$ & 23.0 & $17.4^{*}$ & 20.4 & 20.0 & 21.8 & 15.7 \\
Handbooks / booklets / guides & $\mathbf{1 4 . 2}$ & 17.0 & $11.1^{*}$ & 12.8 & 16.8 & 15.8 & 12.6 \\
Balance & $\mathbf{9 1 . 0}$ & 90.6 & 91.5 & 91.2 & 90.6 & 90.1 & 90.1 \\
Fees and charges & $\mathbf{7 2 . 1}$ & 68.9 & $75.4^{*}$ & 71.1 & 74.0 & 74.3 & $64.0^{*}$ \\
Past performance statistics & $\mathbf{3 9 . 0}$ & 42.0 & 35.8 & 39.8 & 37.4 & 43.5 & $27.4^{* *}$ \\
Info on invest options & $\mathbf{1 7 . 7}$ & 20.9 & $14.2^{* *}$ & 17.3 & 18.4 & 19.4 & 14.1 \\
Other & $\mathbf{0 . 8}$ & 1.0 & 0.7 & 0.9 & 0.7 & 0.9 & 1.3
\end{tabular}




\begin{tabular}{ll|ll|ll|ll} 
& & & & & \\
\hline & All & $25-29 y r s$ & $30-34 y r s$ & Hi_Inc & Low_Inc & English & LOTE \\
Letter from fund & $\mathbf{2 0 . 3}$ & 19.4 & 21.3 & 20.4 & 20.0 & 20.5 & 19.3 \\
Handbooks / booklets / guides & $\mathbf{1 4 . 2}$ & 12.8 & 15.6 & 15.8 & 11.3 & 13.8 & 15.7 \\
Balance & $\mathbf{9 1 . 0}$ & 89.5 & 92.7 & 90.2 & 94.0 & 91.2 & 90.3 \\
Fees and charges & $\mathbf{7 2 . 1}$ & 72.9 & 71.2 & 70.3 & 73.1 & 73.4 & $65.5^{*}$ \\
Past performance statistics & $\mathbf{3 9 . 0}$ & 34.2 & $44.1^{* *}$ & 42.4 & $33.7^{*}$ & 38.8 & 39.8 \\
Info on invest options & $\mathbf{1 7 . 7}$ & 16.0 & 19.4 & 21.9 & $13.8^{*}$ & 17.4 & 19.1 \\
Other & $\mathbf{0 . 8}$ & 0.5 & 1.2 & 0.7 & 1.1 & 0.8 & 0.9 \\
\hline
\end{tabular}

Each observation indicates the proportion of subjects who chose that particular response. Hi_Inc and Low_Inc indicate respondents in the top and bottom tercile of average incomes respectively. Statistical significance of differences between observations for adjacent sub-groups (e.g. between Male and Female sub-groups) is estimated using t-test and $*$ and $* *$ indicate significance at 0.05 and 0.01 percent respectively.

Our final set of results pertain to active engagement with superannuation funds, including changing investment options with the current fund, switching to a different fund, and making voluntary contributions. It is reasonable to assume that respondents exhibiting any of these behaviours first read (and pay attention to) the information supplied by both their fund and by other fund. They are also able to analyse this information (whether individually or in conjunction with other advice). Finally, these respondents are also willing and able to make significant decisions, whether it be changing investment options, or in more extreme cases, switching to a different fund. Given the data presented earlier, and the lack of interest and engagement indicated therein, we do not expect a significant proportion of respondents to exhibit such active involvement with their superannuation funds. Table 6 presents the results associated with changes to superannuation investments. Consistent with earlier results, a vast proportion of respondents make little or no changes to these "default" choices. Although the data does exhibit significant differences between change behaviour between men and women, between high and low income members, and between members with English and LOTE, the overall result supports the notion of disengagement. However, some caution is called for in making inferences as it is likely that some of the respondents may not have changed investment options as they were satisfied with the current investment.

Table 6: Changes to superannuation investments

\begin{tabular}{ll|ll|ll|ll}
\hline & All & Male & Female & Urban & Region & Degree & LowEd \\
When receive statement & $\mathbf{3 . 5}$ & 4.4 & 2.7 & 3.5 & 3.6 & 2.7 & 4.6 \\
Daily or Weekly & $\mathbf{1 . 7}$ & 2.5 & 0.9 & 1.6 & 1.9 & 1.9 & 2.4 \\
Monthly to six monthly & $\mathbf{9 . 3}$ & 13.1 & $5.5^{* *}$ & 11.0 & $6.1^{*}$ & 12.7 & $5.9^{*}$ \\
Yearly & $\mathbf{6 . 4}$ & 6.3 & 6.4 & 6.5 & 6.0 & 7.7 & 5.7 \\
Hardly ever or never & $\mathbf{7 9 . 1}$ & 73.8 & $84.4^{* *}$ & 77.4 & 82.4 & 75.1 & 81.5 \\
& & & & & & & \\
\hline & All & $25-29 y r s$ & $30-34 y$ ys & Hi_Inc & Low_Inc & English & LOTE \\
When receive statement & $\mathbf{3 . 5}$ & 2.9 & 4.2 & 4.4 & 3.2 & 3.8 & 2.5 \\
Daily or Weekly & $\mathbf{1 . 7}$ & 1.9 & 1.5 & 2.1 & 1.2 & 1.1 & $4.4^{* *}$ \\
Monthly to six monthly & $\mathbf{9 . 3}$ & 10.0 & 8.6 & 14.1 & $4.8^{* *}$ & 8.4 & $13.8^{*}$ \\
Yearly & $\mathbf{6 . 4}$ & 5.3 & 7.5 & 7.6 & 4.2 & 6.1 & 7.7 \\
Hardly ever or never & $\mathbf{7 9 . 1}$ & 79.9 & 78.2 & 71.8 & $86.6^{* *}$ & 80.6 & $71.7^{* *}$ \\
\hline
\end{tabular}


Each observation indicates the proportion of subjects who chose that particular response. Hi_Inc and Low_Inc indicate respondents in the top and bottom tercile of average incomes respectively. Statistical significance of differences between observations for adjacent sub-groups (e.g. between Male and Female sub-groups) is estimated using t-test and $*$ and $* *$ indicate significance at 0.05 and 0.01 percent respectively.

In Table 7 we provide some evidence of active engagement by respondents. Panel A indicates that more than $36 \%$ respondents did switch their superannuation fund at least once. All else equal this indicates a higher level of engagement than is obvious from previous results, although clearly some switching would have been necessitated by respondents changing careers and/or employers. Other factors at play could be poor performance by the superannuation fund, unsatisfactory explanation of fund objectives/ goals etc., changes in members' personal objectives etc. In as much as any of these reasons was paramount, it indicates an active response by the participants. A comparison of mean switching frequencies within various sub-groups does not indicate any differences, except that the respondents in the older cohort have switched more often, as have respondents from English speaking backgrounds compared with LOTE respondents. These results are consistent with expectations.

Table 7 Switching superannuation funds

\section{Panel A}

\begin{tabular}{|l|r|r|}
\hline No of Times & Frequency & Percent \\
\hline 0 & 605 & 63.2 \\
\hline 1 & 153 & 15.9 \\
\hline 2 & 91 & 9.5 \\
\hline 3 & 61 & 6.3 \\
\hline 4 & 28 & 3.0 \\
\hline 5 & 12 & 1.2 \\
\hline 6 & 5 & 0.5 \\
\hline 7 & 3 & 0.4 \\
\hline
\end{tabular}

Panel B

\begin{tabular}{rr|rr|rr|rr}
\hline & All & Male & Female & Urban & Region & Degree & LowEd \\
No. of times & $\mathbf{2 . 1}$ & 2.0 & 2.1 & 2.1 & 2.1 & 2.0 & 2.1 \\
\hline & All & $25-29 y r s$ & $30-34 y r s$ & Hi_Inc & Low_Inc & English & LOTE \\
No. of times & $\mathbf{2 . 1}$ & 1.9 & $2.2^{*}$ & 2.1 & 2.1 & 2.2 & $1.7^{* *}$ \\
\hline
\end{tabular}

Each observation indicates the proportion of subjects who chose that particular response. Hi_Inc and Low_Inc indicate respondents in the top and bottom tercile of average incomes respectively. Statistical significance of differences between observations for adjacent sub-groups (e.g. between Male and Female sub-groups) is estimated using t-test and $*$ and $* *$ indicate significance at 0.05 and 0.01 percent respectively.

On a related note, we expected that a respondent would monitor her accounts more actively, and subsequently exhibit higher likelihood of changing her choice, if she were able to access information more readily via extensive use of smart devices etc. However the empirical evidence did not support this expectation and more device-savvy respondents were no more likely to be actively involved with their superannuation accounts than ones without such access (results untabulated). 
Making voluntary contributions to one's superannuation fund can be considered as an integral part of respondent behaviour. It is important to note that a respondent who makes voluntary contributions is also more likely to be actively concerned about his account, retirement, and be generally more aware of issues related to financial planning. However the notion that some respondents knowingly choose not to make any voluntary contribution cannot be entirely discounted - these employees could be just as aware of all the pertinent issues as the ones making voluntary contributions but make a different choice.

The results are presented in Table 8. Almost two-thirds (62.6\%) of respondents have never made a voluntary contribution. There are significant behavioural differences between degree and nondegree holders with respect to voluntary contributions as degree holders tend to make such contributions more frequently. Perhaps the most striking result is the clear demarcation between the voluntary contribution behaviour of the younger and older cohorts. Older respondents (30-34 years) contribute more frequently and are also more aware of the ability to do so, although they are less sure about whether they have done this in the past. This is consistent with earlier literature that observes that "the respondents had more difficulty answering the multiple-choice question related to voluntary contributions limits. ... In this case, only $26 \%$ of the total sample correctly responded that for most people there are no limits placed on their voluntary contributions, only tax consequences if they contribute beyond a certain amount" (Agnew et al., 2013). We also note that the sample size for this analysis is low $(n=160)$, making it difficult to draw any firm conclusions.

Table 8: Voluntary contribution to superannuation funds

\begin{tabular}{lr|ll|ll|ll}
\hline & All & Male & Female & Urban & Region & Degree & LowEd \\
Have made one or more VCs & $\mathbf{1 7 . 4}$ & 18.2 & 16.5 & 17.3 & 17.5 & 21.2 & $9.9^{* *}$ \\
VC regularly & $\mathbf{1 9 . 2}$ & 19.8 & 18.6 & 19.9 & 17.9 & 22.9 & $12.1^{* *}$ \\
Have never made VC & $\mathbf{6 2 . 6}$ & 57.6 & $67.6^{* *}$ & 60.9 & 65.9 & 59.6 & $69.0^{*}$ \\
Did not know VC were possible & $\mathbf{5 . 4}$ & 7.5 & $3.3^{* *}$ & 5.8 & 4.7 & 5.2 & 6.7 \\
Don't know if VC has been made & $\mathbf{1 5 . 4}$ & 17.6 & 13.1 & 16.8 & 12.6 & 14.9 & 15.1 \\
Estimated percentage of balance & $\mathbf{1 3 . 7}$ & 15.9 & 11.1 & 14.3 & 12.6 & 14.7 & $9.4^{*}$ \\
made up of VCs & & & & & & & \\
\hline & $\mathbf{A l l}$ & $25-$ & $30-34$ yrs & Hi_Inc & Low_Inc & English & LOTE \\
Have made one or more VCs & & $29 y r s$ & & & & & \\
VC regularly & $\mathbf{1 7 . 4}$ & 13.1 & $22.0^{* *}$ & 21.2 & 15.1 & 17.9 & 15.0 \\
Have never made VC & $\mathbf{1 9 . 2}$ & 15.3 & $23.4^{* *}$ & 22.3 & 18.0 & 19.2 & 19.4 \\
Did not know VC were possible & $\mathbf{6 2 . 6}$ & 67.9 & $56.9^{* *}$ & 60.7 & 65.4 & 63.0 & 60.7 \\
Don't know if VC has been made & $\mathbf{5 . 4}$ & 7.4 & $3.2^{* *}$ & 6.7 & 6.1 & 4.7 & $8.6^{*}$ \\
Estimated percentage of balance & $\mathbf{1 5 . 4}$ & 12.6 & $18.4^{*}$ & 12.3 & 14.2 & 14.7 & 18.7 \\
made up of VCs & $\mathbf{1 3 . 7}$ & 12.3 & 14.8 & 16.9 & 14.0 & 13.9 & 12.9 \\
\hline
\end{tabular}

Each observation indicates the proportion of subjects who chose that particular response. Hi_Inc and Low_Inc indicate respondents in the top and bottom tercile of average incomes respectively. Statistical significance of differences between observations for adjacent sub-groups (e.g. between Male and Female sub-groups) is estimated using t-test and $*$ and $* *$ indicate significance at 0.05 and 0.01 percent respectively.

\footnotetext{
${ }^{5}$ If and only if a respondent had a balance in their voluntary amount, this amount was divided by their total superannuation funds and expressed as a percentage.
} 


\section{Conclusions}

Young adults in our study appear to be unengaged by and uninterested in their superannuation accounts and by implication, in issues related to retirement. Most respondents do not check their accounts regularly or change investment options. One-third read most or all of their periodic statements and the vast majority do check the balance of their account on these statements. Most extra material provided by superannuation funds is not read. Consistent with lack of engagement, most have never contemplated switching their superannuation accounts to a different fund, although some of this behavior may be attributed to at least some respondents being satisfied with their current fund. Behaviour consistent with a lack of interest is also evident in a low response rate to the question relating to voluntary contributions (only $16 \%$ of those surveyed responded to this query), and almost two-thirds of these respondents have never made a voluntary contribution. Although this behavior does seem to change as respondents get older, the overall conclusion seems to be consistent with the idea that superannuation is not a major priority at this stage in the lives of the respondents.

Given that retirement planning is necessarily difficult and uncertain, it seems that more must be done to focus on the early stages of retirement wealth accumulation to prepare young adults for later life. Our research indicates that some sub-groups exhibit particularly undesirable behaviour towards their superannuation accounts. These include lower educated and younger respondents (25-29 years old), but these sub-groups are part of the compulsory superannuation system. An additional focus on education for those in these groups aimed at minimising the disadvantages that result from lower levels of knowledge about superannuation, and making them more aware of the informed choices they can make subsequently may prepare them much better for later life.

\section{References}

Agnew, J., H Bateman and S Thorp, 'Financial Literacy and Retirement Planning in Australia' (2013) 6(2) Numeracy: Advancing Education in Quantitative Literacy Article 7.

Australian Prudential Regulation Authority, APRA Insight: Issue One 2014 (2014), 16.

Bateman, H., Eckert, C., Geweke, J., Louiviere, J., Thorp, S. and Satchell, S. (2012) Financial competence and expectations formation: Evidence from Australia. The Economic Record

88(280): 39-63. https://doi.org/10.1111/j.1475-4932.2011.00766.x

Deloitte Actuaries and Consultants, "Dynamics of the Australian Superannuation System: The Next 20 Years: 2013-2033" (September 2013), 1 (measured by pool of assets).

Ntalianis, M. and V Wise, 'The Role of Financial Education in Retirement Planning' (2011), 5 Australasian Accounting Business and Finance Journal 23.

Ntalianis, M., 'An Investigation of Financial Education Model for Superannuation Decisions' (2011) International Review of Business Research Papers, vol. 7, no. 1, pp. 239-250.

Parrish, T. and Delpachitra, S. 2012, 'On Selection of Superannuation Fund: Impact of Choice and Information', Economic Papers, vol. 31 issue 3, pp. 369-379. https://doi.org/10.1111/j.1759-3441.2012.00181.x 
The Social Research Centre, "ANZ Survey of Adult Financial Literacy in Australia" (ANZ, December 2011)

Tustin, M., A Hinds and A-S Songsil, 'Gen Y \& Superannuation: Why Won't They Engage? Quantitative Report' (Colmar Brunton, 2014).

Worthington, A. C., 'Knowledge and Perceptions of Superannuation in Australia' (2008), 31 Journal of Consumer Policy 349. 